\title{
Study on Influential Factors of Jiangsu Urban Users in Selection of IPTV Based on the Conversion Cost Theory
}

\author{
Wang Feng ${ }^{(1)}$ \\ Hohai University, Nanjing, China \\ email:18357825@qq.com
}

Keywords: IPTV Influence Factors; Use diffusion; Conversion Cost Theory.

\begin{abstract}
This article researchs influence factors of townsman's IPTV business selection in Jiangsu province through the questionnaire and other methods.It can be found that there was a significant positive correlation between using diffusion and switching intention in Jiangsu user; The relationship of financial switching cost and consumer switching intention shows no obvious correlation; There was a linear negative correlation between procedural switching costs and consumer switching intention. Among these factors, the negative relationship between switching costs and consumer switching intention is the most significant.Combined with the research results, the article puts forward specific suggestions for Jiangsu city to develop IPTV services, especially in the aspect of promoting close customer relationship and enriching pricing models, etc.
\end{abstract}

\section{Introduction}

In recent years, the number of phone users of Jiangsu communication industry has been reaching saturation with the depression of voice service. The growing rate of telecom business revenue has been much lower than that of GDP and the industry has entered to a slow growth period, which forces the communication industry to accelerate its transition and look for new business with great development prospect, so as to increase the business revenue effectively.

As a typical product of triple playIPTV owns the advantages of rich program sources, strong interactivity, and courteous service compared with other traditional cable televisions. It is also widely recognized as one of the major transition businesses with great development potential in the communication industry. This paper aims to study the influencing factors for Jiangsu urban users to choose IPTV service as well as the relationship among the factors from the perspective of consumers, so as to help the telecom operators or regulators to clarify the current Jiangsu IPTV user development factors as well as its development direction and acting point.

\section{Research hypothesis}

As stated before, IPTV and traditional cable television are in no difference in terms of the business type. In this case, the development of new users, the retaining of existing customers and the increasing of their application amount are becoming very important, which leads to the competitors trying hard to take existing users from each other to increase their own market share. Therefore, the telecom operators of IPTV service should not only take customers from competitors positively but also try hard to retain their own existing customers to make them not tempted by opponents. Then the conversion cost state of the industry is exactly the topic that needs to be discussed actively by the academia and the industrial circle. While the improvement of customer product application degree coincides with the concept of use-diffusion newly put forward by the academia. Therefore, the study proposes the following hypotheses on the basis of the relevant theories:

\footnotetext{
(1) About the author:

Name: Wang Feng; Birth date: December 1979; Gender: Female; Birthplace: Jiangsu Lianyungang;

Education: Ph.D. in Reading; school: Hohai University ; Research: Technology Economics and Management; title:

Intermediate economist; college level: the national "211 Project "key construction universities 
H1: In the selection of television service, the higher the use-diffusion of consumers is, the stronger the provider conversion intention by consumers will be.H2: In the selection of IPTV service, when consumers perceive that the procedure conversion cost is becoming higher, they will show less interest in changing the television service provider. H3: the financial conversion cost perceived by consumers cannot affect their conversion intention greatly.H4: In the selection of IPTV service, the higher the relationship conversion cost perceived by the consumers is, the lower intention they will have in changing the television service provider. H5: In the IPTV service selection, the higher the use innovativeness intention of consumers is, the higher the product use diffusion degree will be.H6: In the IPTV service selection, the higher the use innovativeness intention of consumers is, the higher the perceived procedure conversion cost will be. H7: In the IPTV service selection, the higher the use innovativeness intention of consumers is, the higher the perceived financial conversion cost will be.H8: In the IPTV service selection, the higher the use innovativeness intention of consumers is, the higher the perceived relationship conversion cost will be.H9: In the IPTV service selection, the higher the use innovativeness intention of consumers is, the higher the product motivation conversion will be.

\section{Investigation methods and questionnaire design}

Table 1 - distribution table of formal research samples

\begin{tabular}{|c|c|c|c|c|c|c|}
\hline Suzhou (Southern Jiangsu) & \multicolumn{2}{|c|}{ Male } & \multicolumn{2}{c|}{ Female } & \multicolumn{2}{c|}{ Total } \\
\hline Under age 14 & $2.27 \%$ & 6 & $1.89 \%$ & 5 & $4.17 \%$ & 11 \\
\hline Age 15-24 & $11.74 \%$ & 31 & $10.23 \%$ & 27 & $21.97 \%$ & 58 \\
\hline Age 25-34 & $12.88 \%$ & 34 & $12.12 \%$ & 32 & $25.00 \%$ & 66 \\
\hline Age 35-49 & $17.42 \%$ & 46 & $15.15 \%$ & 40 & $32.58 \%$ & 86 \\
\hline Over age 50 & $9.09 \%$ & 24 & $7.20 \%$ & 19 & $16.29 \%$ & 43 \\
\hline & $53.41 \%$ & 141 & $46.59 \%$ & 123 & $100.00 \%$ & 264 \\
\hline Lianyungang (Northern & \multicolumn{2}{|c|}{ Male } & \multicolumn{2}{|c|}{ Female } & \multicolumn{2}{c|}{ Total } \\
\hline Under age 14 & $2.38 \%$ & 5 & $1.79 \%$ & 3 & $4.17 \%$ & 8 \\
\hline Age 15-24 & $11.31 \%$ & 21 & $8.93 \%$ & 17 & $20.24 \%$ & 38 \\
\hline Age 25-34 & $13.69 \%$ & 25 & $13.10 \%$ & 24 & $26.79 \%$ & 49 \\
\hline Age 35-49 & $17.26 \%$ & 31 & $14.88 \%$ & 27 & $32.14 \%$ & 58 \\
\hline Over age 50 & $8.93 \%$ & 16 & $7.74 \%$ & 14 & $16.67 \%$ & 30 \\
\hline & $53.57 \%$ & 98 & $46.43 \%$ & 85 & $100.00 \%$ & 184 \\
\hline Nantong (Central Jiangsu) & \multicolumn{2}{|c|}{ Male } & \multicolumn{2}{|c|}{ Female } & \multicolumn{1}{c|}{ Total } \\
\hline Under age 14 & $1.96 \%$ & 3 & $1.96 \%$ & 3 & $3.92 \%$ & 6 \\
\hline Age 15-24 & $11.76 \%$ & 18 & $10.46 \%$ & 16 & $22.22 \%$ & 34 \\
\hline Age 25-34 & $13.07 \%$ & 20 & $10.46 \%$ & 16 & $23.53 \%$ & 36 \\
\hline Age 35-49 & $16.99 \%$ & 26 & $16.34 \%$ & 25 & $33.33 \%$ & 51 \\
\hline Over age 50 & $9.15 \%$ & 14 & $7.84 \%$ & 12 & $16.99 \%$ & 26 \\
\hline & $52.94 \%$ & 81 & $47.06 \%$ & 72 & $100.00 \%$ & 153 \\
\hline
\end{tabular}

This study adopted the spot investigation and questionnaire with 200 questionnaires respectively issued to three cities separately selected from Southern Jiangsu, Central Jiangsu and Northern Jiangsu, for the purpose of realizing data collection of use diffusion, switching cost, use innovativeness and other variables with structured questionnaire and studying influencing factors of Jiangsu City users' selection of IPTV service.

The comparison of use innovativeness measures, at the earliest, was made by 44 questions developed by Scholar Price and Ridgway ${ }^{[1]}$. Thereafter, empirical analysis was continuously made by Price and Ridgway with the application of this scale, with the overall reliability of its result up to cronbach's alpha 0.91 and alphas value of each subscale ranging from 0.56 to 0.86 . Shih and Venkatesh $^{[2]}$ identified use innovativeness as one of the aspects of the comparison of use diffusion — the pre-exponential factor of diversified use; moreover, on the basis of questions developed by Price and Ridgway, five questions selected respectively from the five aspects through random drawing were restructured into a five-question group for the comparison of use innovativeness which 
was the scale with the overall reliability up to Cronbach's alpha 0.81 .The five-question short scale of Shih and Venkatesh was to be applied to this study as its comparative basis.Nevertheless, the comparison between dimensions of switching cost and switching intention in structured questionnaire was designed on the basis of the scale used in the study conducted by Burnham et al. ${ }^{[3]}$. Burnham et al. (2003) used scale classifications with the reliability of each dimension ranging between Cronbach $\alpha 0.71$ to 0.87 . The formal survey questionnaires of this study were filled out in one month from March 24, 2012 to April 24, 2012, with 600 questionnaires issued and 600 valid questionnaires retrieved. The distribution table of samples was showed as Table 1.

\section{Results analyses}

With the application of Linear Structural Relations Model, this study analyzed the relation among use innovativeness, use diffusion, switching cost and switching intention, including the coordination of whole model of relation among variables and the display of the strength of relation among variables. The statistical software applied herein was Lisrel8.51.

The results showed that use innovativeness had a significantly positive influence on use diffusion (Phi=0.59, $\mathrm{p}<0.001)$. Therefore, research hypothesis 5 (H5) was true. The hypothesis that use innovativeness had a significantly positive influence on procedural switching costs was false $(\mathrm{Phi}=0.01, \mathrm{p}>0.05)$, therefore, research hypothesis 6 (H6) was false. It was true that use innovativeness had a significantly positive influence on financial switching costs (Phi $=0.17$, $\mathrm{p}<0.001)$, therefore, research hypothesis 7 (H7) was true. The hypothesis that use innovativeness had a significantly positive influence on relational switching costs was true $(\mathrm{Phi}=0.29, \mathrm{p}<0.001)$, therefore, research hypothesis 8 (H8) was true. Use innovativeness had a non-significantly negative influence on relational switching costs $(\mathrm{Phi}=-0.11, \mathrm{p}>0.05)$, therefore, research hypothesis 9 (H9) was false.

Table 2 - the holistic coordination of the model and the coefficient of structure model

\begin{tabular}{cc}
\hline & The inclusive fitness \\
\hline 2 & 697.27 \\
Df & 143 \\
$2 / d f$ & 4.87 \\
CFI & 0.87 \\
GFI & 0.89 \\
AGFI & 0.85 \\
NFI & 0.84 \\
RMR & 0.14 \\
RMSEA & 0.080 \\
\hline
\end{tabular}

\begin{tabular}{|c|c|c|c|}
\hline The inclusive fitness & Parameter values & $\mathrm{t}$ value & Verification results \\
\hline Use diffusion $\rightarrow$ Switching intention & 0.23 & $2.75 * *$ & H1 was true \\
\hline Procedural switching costs $\rightarrow$ Switching intention & -0.21 & $-4.62 * * *$ & $\mathrm{H} 2$ was true \\
\hline Financial switching costs $\rightarrow$ Switching intention & 0.06 & 1.52 & H3 was true \\
\hline Relational switching costs $\rightarrow$ Switching intention & -0.40 & $-7.14 * * *$ & H4 was true \\
\hline Use innovativeness $\rightarrow$ Use diffusion & 0.59 & $4.96^{* * *}$ & H5 was true \\
\hline Use innovativeness $\rightarrow$ Procedural switching costs & 0.01 & 0.27 & H6 was false \\
\hline Use innovativeness $\rightarrow$ Financial switching costs & 0.17 & $3.49 * * *$ & $\mathrm{H} 7$ was true \\
\hline Use innovativeness $\rightarrow$ Relational switching costs & 0.29 & $3.97 * * *$ & H8 was true \\
\hline Use innovativeness $\rightarrow$ Switching intention & -0.10 & -1.24 & H9 was false \\
\hline
\end{tabular}

(Note: numbers in brackets are $t$ value; * means $|t|>1.645$, $p<0.05$; ** means $|t|>2.326, p<0.01$; *** means $|t|>3.090$, $\mathrm{p}<0.001)$ 


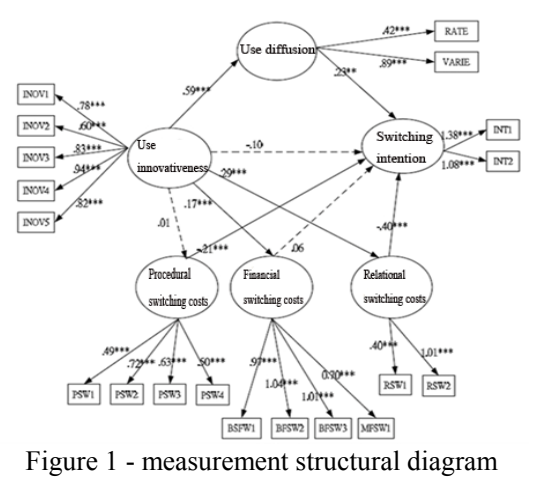

In addition, as for $\mathrm{H} 1$, it was true that use diffusion had a significantly positive influence on switching intention ( $\mathrm{Phi}=0.23, \mathrm{p}<0.01$ ). Moreover, the comparisons of influences of three kinds of switching costs on switching intention were made in this model. It was true that procedural switching costs had a significantly negative influence on switching intention (Phi=-0.21, $\mathrm{p}<0.001)$, therefore, research hypothesis $2(\mathrm{H} 2)$ was true. As for $\mathrm{H} 3$, the hypothesis that financial switching costs had no significant influence on switching intention was true $(\mathrm{Phi}=0.06, \mathrm{p}>0.05)$. As for $\mathrm{H} 4$, it was true that relational switching costs had a significantly negative influence on switching intention (Phi=-0.40, $\mathrm{p}<0.001)$. Furthermore, in the comparative aspect of coefficient, relational switching costs were stronger than procedural switching costs, and financial switching costs were the weakest.

\section{Conclusion and suggestions}

Based on the above research conclusions, below strategy suggestions were put forward to develop IPTV service users in Jiangsu City.This paper mainly made further analyses of the relations between use diffusion \& three kinds of switching costs and switching intention in research results, since relevant strategy suggestions focusing on the positive correlation between use innovativeness and use diffusion had been previously proposed in other articles.

1.There was a significant relation between relational switching costs and switching intention of consumers.Therefore, two suggestions were proposed as follows:(a)Strengthening brand management. (b)Close user relations.

2.The study found that financial switching costs had weaker influence on switching intention of consumers, which showed that reducing price to gain or keep users at this stage had no remarkable effect. Presently, IPTV service mainly adopted the pricing model of monthly payment. Recommendation was made to further enrich pricing models and meet different demands of consumers.

\section{References}

[1] Price,L.L.and Ridgeway,N.M..Development of a Scale to Measure Use Innovativeness in Advances in Consumer Research[J]. Richard P. Bagozzi and Alice Tybout, eds. Ann Arbor. Association for Consumer Research,1983,10:679-84.

[2] Shih,C.F. and Venkatesh,A..Beyond Adoption: Development and Application of a Use-Diffusion Model[J]. Journal of Marketing,2004, 68:59-72.

[3] Burnham, T. A.,Frels,J. K. and Mahajan, V. .Consumer Switching Costs: A Typology,Antecedents, and Consequences[J]. Journal of the Academy of Marketing Science, 2003, 31(2);109-126.

[4]Gehrig, T. et al.. Differentiation-Induced Switching Costs and Poaching [J].Journal of Economics and Management Strategy, 2004, 13: 635-655.

[5] Kim, M. K., Park, M. C. and Jeong, D. H. .The Effects of Customer Satisfaction and Switching Barrier on Customer Loyalty in Korean Mobile Telecommunication Services. Telecommunications Policy[J]. $2004,28: 145-159$. 